\title{
BIOMECHANICAL ANALYSIS OF DIFFERENT PROSTHETIC TECHNOLOGIES FOR TRANS-FEMORAL AMPUTEES DURING SLOPE DESCENT
}

\author{
Nadine Stech ${ }^{* 1}$, Michael McGrath ${ }^{1}$, Piotr Laszczak ${ }^{1}$, Alan Kercher ${ }^{2}$, Saeed Zahedi ${ }^{1}$, David Moser ${ }^{1}$ \\ ${ }^{1}$ Endolite Technology Centre, Basingstoke, UK \\ ${ }^{2}$ Endolite North America, Miamisburg, OH, USA
}

*Email: nadine.stech@blatchford.co.uk

\section{INTRODUCTION}

Lower limb amputees have different biomechanics to able-bodied people when walking on slopes ${ }^{1,2}$, often struggling to negotiate different gradients safely. Loss of proprioception and muscular control contributes to this issue, which is a particular problem for trans-femoral amputees, where both ankle and knee joints are absent. Studies have shown that prosthetic technologies can have benefits for slope negotiation. The aim of this study was to isolate the specific effects of different trans-femoral prosthetic technologies, by applying each additional mechanism incrementally.

\section{METHODS}

Four prosthetic conditions were tested in a randomised order:

(1) A rigid ankle, ESR foot (Esprit, Endolite - RA)

(2) A hydraulic ankle-foot with constant resistances to $\mathrm{PF}$ and $\mathrm{DF}$ (HA)

(3) A microprocessor-controlled hydraulic anklefoot (Elan, Endolite - MPF) that varied resistances to $\mathrm{PF}$ and DF

(4) A microprocessor-controlled, integrated limb system (Linx, Endolite - MPL) that both varied resistances to PF and DF at the 'ankle' and applied a yielding support at the prosthetic knee during step-to-step transition.

For the cohort of trans-femoral amputees, a gait analysis motion capture system and a slope-integrated force plate were used to measure kinematic and kinetic parameters as the participant walked down a $5^{\circ}$ slope at their comfortable walking speed. A $5^{\circ}$ slope was selected as this aligns with the ADA regulations regarding disability access ramps - a common real-life environmental barrier.

\section{RESULTS}

Each incremental change in technology showed distinct biomechanical effects on the gait of the user. The transition from RA to HA showed a better foot compliance with the ground, reducing the time taken to achieve foot flat and a smoother progression of the shank

segment with HA. With the MPF, the transition from DF to PF 'ankle' moment occurred earlier, implying a smaller resistance to PF movement, further enhancing ground compliance, and a greater resistance to DF movement, implying a 'braking' action to control shank rotation. Further to just the MPF, the MPL introduced yielding at the knee during late stance phase, which was evident in the kinematic and kinetic knee joint curves. The rate of flexion in late stance was reduced, absorbing less joint power, allowing for a controlled transition of body mass from the prosthetic limb to the sound limb.
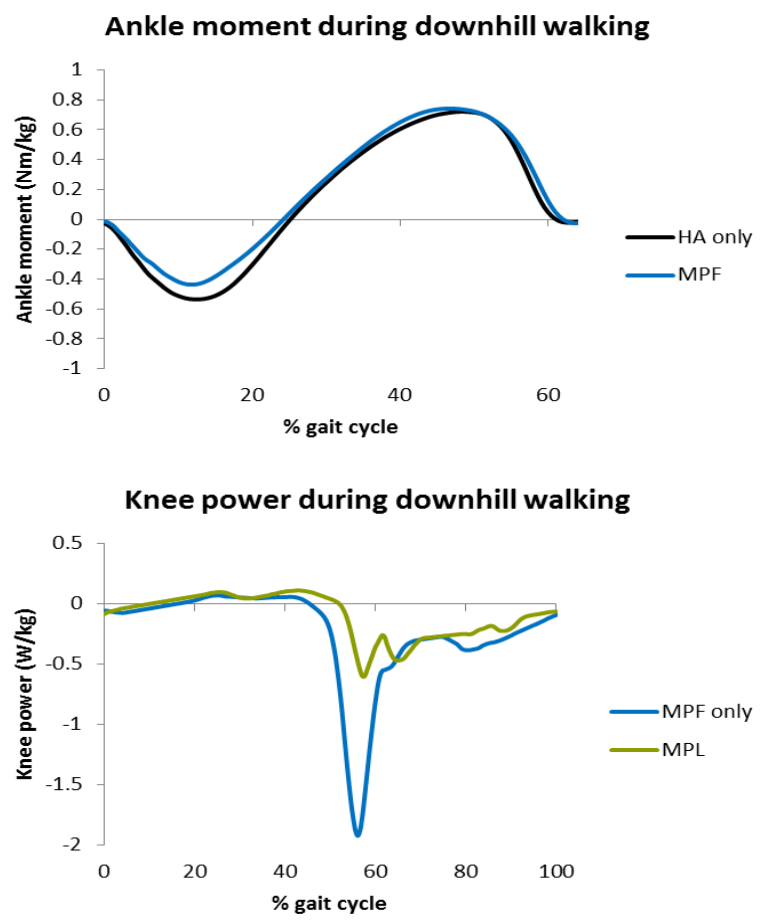

Figure 1: (TOP) ankle moment curves showing the effect of MPF (blue) compared to HA (black) and (BOTTOM) knee power curves showing the effect of MPL with knee yielding (green) compared to MPF only (blue). 


\section{CONCLUSION}

This study isolated the individual effects of incremental increases in technologies design to aid ramp negotiation for trans-femoral amputees. These technologies have been shown to provide greater bodyweight support by replicating natural muscular control at the prosthetic 'ankle' and knee joints.

\section{SIGNIFICANCE}

Advanced prosthetic technology can provide benefits for trans-femoral amputees when negotiating slopes. Understanding these effects helps to make informed prescriptions.

\section{REFERENCES}

1.Vickers et al. Elderly unilateral transtibial amputee gait on an inclined walkway: a biomechanical analysis. Gait Posture. 2008;27(3):518-529. DOI:10.1016/j.gaitpost.2007.06.008

2.Vrieling et al. Uphill and downhill walking in unilateral lower limb amputees. Gait Posture. 2008;28(2):235-242. DOI:10.1016/j.gaitpost.2007.12.006

3. Struchkov V, Buckley JG. Biomechanics of ramp descent in unilateral trans-tibial amputees: Comparison of a microprocessor controlled foot with conventional ankle-foot mechanisms. Clin Biomech. 2016;32:164-170 DOI:10.1016/j.clinbiomech.2015.11.015

4.Highsmith et al. Ramp descent performance with the C-Leg and interrater reliability of the Hill Assessment Index. Prosthet Orthot Int. 2013;37(5):362-8. DOI: $10.1177 / 0309364612470482$

\section{DISCLOSURE}

The Authors are employees of Endolite North America or Blatchford (the parent company of Endolite North America); the manufacturer of the prosthetic devices used in this study. 